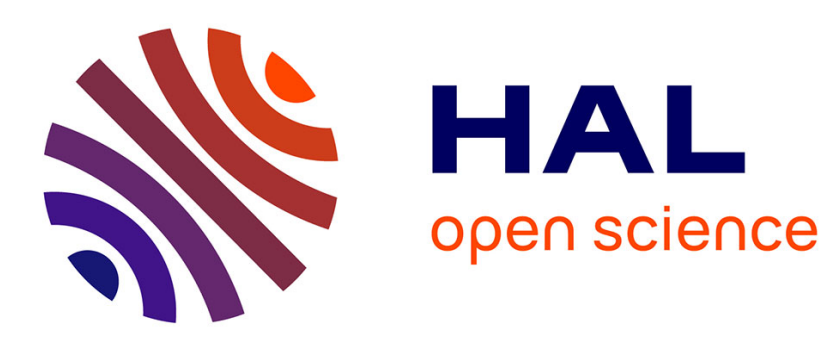

\title{
The risk of systemic infections requiring hospitalisation in children with atopic dermatitis: a Danish retrospective nationwide cohort study
}

Catherine Droitcourt, I Vittrup, A Dupuy, A Egeberg, Melilotus Thyssen

\section{- To cite this version:}

Catherine Droitcourt, I Vittrup, A Dupuy, A Egeberg, Melilotus Thyssen. The risk of systemic infections requiring hospitalisation in children with atopic dermatitis: a Danish retrospective nationwide cohort study. British Journal of Dermatology, 2021, 185 (1), pp.119-129. 10.1111/bjd.19825 . hal-03129777

\section{HAL Id: hal-03129777 \\ https://hal.science/hal-03129777}

Submitted on 19 Feb 2021

HAL is a multi-disciplinary open access archive for the deposit and dissemination of scientific research documents, whether they are published or not. The documents may come from teaching and research institutions in France or abroad, or from public or private research centers.
L'archive ouverte pluridisciplinaire HAL, est destinée au dépôt et à la diffusion de documents scientifiques de niveau recherche, publiés ou non, émanant des établissements d'enseignement et de recherche français ou étrangers, des laboratoires publics ou privés. 
DR CATHERINE DROITCOURT (Orcid ID : 0000-0001-6714-6643)

DR ALEXANDER EGEBERG (Orcid ID : 0000-0001-8257-1816)

Article type : Original Article

The risk of systemic infections requiring hospitalisation in children with atopic dermatitis: a Danish retrospective nationwide cohort study

Running head: Risk of hospitalised systemic infections in Danish children with atopic dermatitis

C. Droitcourt, ${ }^{1,2,3,4}$ I. Vittrup,,$^{1,2}$ A. Dupuy, ${ }^{1,2,3,4}$ A. Egeberg ${ }^{1,2}$ and J.P. Thyssen ${ }^{1,5}$

${ }^{1}$ Department of Dermatology and Allergy, Herlev and Gentofte Hospital, University of Copenhagen, Hellerup, Denmark

${ }^{2}$ Copenhagen Research Group for Inflammatory Skin (CORGIS), Herlev and Gentofte Hospital, Hellerup, Denmark

${ }^{3}$ Department of Dermatology, CHU Rennes, F35000 Rennes, France

${ }^{4}$ University of Rennes, EA 7449 REPERES “Pharmacoepidemiology and Health Services Research", F35000 Rennes, France

${ }^{5}$ Department of Dermatology and Venereology, Bispebjerg Hospital, University of Copenhaguen, Copenhaguen, Denmark

Corresponding author: Dr Catherine Droitcourt

Email: catherine.droitcourt@chu-rennes.fr

Funding sources: The study was supported by a research grant from the International Society of Atopic Dermatitis (ISAD) 
Conflicts of Interest: Catherine Droitcourt has received Honoria from Sanofi-Genzyme. Ida Vittrup has received salary from a research grant from Regeneron Pharmaceuticals. Alain Dupuy: has attended advisory boards for Sanofi-Genzyme. Alexander Egeberg has received research funding from Pfizer, Eli Lilly, the Danish National Psoriasis Foundation, and the Kgl Hofbundtmager Aage Bang Foundation, and honoraria as consultant and/or speaker from AbbVie, Almirall, Leo Pharma, Samsung Bioepis Co., Ltd., Pfizer, Eli Lilly and Company, Novartis, Galderma, Dermavant, Bristol-Myers Squibb, Mylan, UCB, and Janssen Pharmaceuticals. Jacob Thyssen has attended advisory boards for Sanofi-Genzyme, Regeneron, LEO Pharma, Union Therapeutics, Pfizer, AbbVie and Eli Lilly \& Co, and received speaker honorarium from LEO Pharma, Regeneron, Abbvie and Sanofi-Genzyme, and been an investigator for Sanofi-Genzyme, Eli Lilly \& Co, LEO Pharma, Pfizer and AbbVie.

\section{What's already known about this topic?}

Few studies have suggested an association between atopic dermatitis and extra-cutaneous infections in children; they are, however, based on self-report questionnaires or focused on outpatient infectious diseases.

\section{What does this study add?}

Children with $\mathrm{AD}$ have an increased risk of systemic infections requiring hospitalisation including respiratory tract, gastrointestinal, urinary tract and musculoskeletal ones. The associations remained, even after taking into account atopic comorbidities and immunosuppressant treatment for AD. 


\section{Abstract}

\section{Background}

Certain infections can trigger worsening of atopic dermatitis (AD). Further, an increased risk of extra-cutaneous infections has been suggested among children with $\mathrm{AD}$, but data are sparse.

\section{Objectives}

To examine whether hospital managed pediatric $\mathrm{AD}$ is associated with increased risk of extracutaneous infections in childhood requiring hospitalisation.

\section{Methods}

Nationwide based cohort study using Danish registries. All children aged under 18 years with a hospital in- or outpatient diagnosis of $\mathrm{AD}$ and reference children without hospital diagnosis of $\mathrm{AD}$ were matched on gender and age at first AD diagnosis date (1:10). Children were included from January 1, 1995 to December 31, 2016 and followed up until December 31, 2017.

Study outcomes were extra-cutaneous infections that lead to hospitalisation. The severity of AD was defined by dispensations of $\mathrm{AD}$ treatments.

\section{Results}

Of 19,415 AD children (median follow-up 7.4, interquartile range (IQR) 3.3-13.3 years) and 194,150 non-AD children (median follow-up 7.7, IQR 3.6-13.5 years), 56\% were boys and 50\% aged under 2 years. In adjusted analyses, children with $\mathrm{AD}$ had increased occurence of lower respiratory (aHR (adjusted hazard ratio) $=1.79,95 \%$ confidence interval (CI95\%) 1.65-1.94), upper respiratory $\quad(\mathrm{aHR}=1.59$, CI95\% 1.34-1.88), urinary tract $(\mathrm{aHR}=1.34$ CI95\% 1.16-1.54), musculoskeletal (aHR=1.33 CI95\% CI95\% 1.06-1.66), and gastrointestinal infections (aHR=1.24, CI95\% 1.14-1.35), compared with children without a hospital diagnosis of AD. The associations did not clearly vary with the AD severity. The absolute risk difference per 10,000 person-years was 26.4 (CI95\% 23.0-29.8) for lower respiratory, 3.1 (CI95\% 1.6-4.7) for upper respiratory, 3.6 (CI95\% 1.8-5.4) for urinary tract, 0.9 (CI95\% 0.2-2.0) for musculoskeletal and 8.7 (CI95\% 5.711.7) for gastrointestinal infections.

\section{Conclusions}


Children with hospital-managed AD have an increased risk of systemic infections that lead to hospitalization. The absolute risk was generally low. 


\section{Introduction}

Atopic dermatitis (AD) is a highly prevalent chronic inflammatory skin disease of childhood that affect up to $20 \% .{ }^{1,2}$ Children with $\mathrm{AD}$ have a severity-dependent increased risk of skin infections due to colonization with bacteria (e.g. Staphylococcus aureus) or viral activity (herpes simplex, eczema herpeticum), in part due to skin barrier impairment that increases $\mathrm{pH}$, but also an altered cellular immunity. ${ }^{1,3,4-6}$

An association between $\mathrm{AD}$ and systemic infections has also been suggested. ${ }^{7}$ This may be due to dysregulation of the innate and adaptative immunity, ${ }^{8}$ comorbid atopic respiratory disorders, and use of systemic immunosuppressive treatments. The few studies finding an association between childhood $\mathrm{AD}$ and systemic infections are based on patient self-report or focused on infections that were managed outside of a hospital setting. ${ }^{9-11}$ There are very limited data concerning risk of physician-confirmed infections and infections requiring hospitalisation in patients with AD. ${ }^{12}$ We examined whether children with a hospital diagnosis of AD have an increased risk of developing systemic infections requiring hospitalisation compared to a population of children without hospital diagnosed AD.

\section{Methods}

\section{Study design and data sources}

We performed a population-based cohort study. The source was the Danish registries covering the entire Danish population (approximatively 5.5 millions of individuals) and linked together through a unique ten-digit personal number given to each Danish resident (number CPR, Civil Personal Register) at birth or immigration. ${ }^{13}$ The registries contain anonymized, individual-level data, including demographic data (gender, dates of birth and death);13,14 inpatient, outpatient, and emergency room visits including the diagnoses, from all public and a number of private hospitals in the Danish National Patient Register (DNPR); ${ }^{15-18}$ all drug dispensations from Danish pharmacies (according to the Anatomical Therapeutic Chemical classification, ATC) with their date of dispensations and the prescriber in the Danish National Prescription Register (DNPrR); ${ }^{19}$ all hospital procedures (including hospital-based pharmacological treatment) in the DNPR; the household and personal income data in the Income Statistic Register (ISR). ${ }^{20}$

Study population and exposure 
All children born in Denmark between January 1, 1995 and December 31, 2016 recorded in the nationwide Danish registries (source population, 1,439,718 children) were eligible for inclusion in the cohort study.

\section{Definition of exposed cohort:}

The exposed cohort included all children (under 18 years) with a hospital diagnosis (in- or outpatient) of $\mathrm{AD}$ in childhood (before the age of 18 years) recorded in the DNPR, between January 1, 1995 and December 31, 2016. The diagnosis of AD was defined as the first diagnostic code of AD (L20.x, primary or associated diagnosis, according the International Classification of Diseases, 10th version, (ICD-10)) recorded and made by a hospital physician, before the age of 18 years. The positive predictive value of an AD diagnosis in childhood in the Danish registries is $98 \% .^{21}$

\section{Definition of matched unexposed cohort:}

Each child with a hospital diagnosis of $\mathrm{AD}$ was randomly matched to ten reference children from the source population on birth date and gender at the date of $\mathrm{AD}$ diagnosis for the corresponding child with AD, identified through the Danish National Patient Register (reference population). The index date was the date of AD diagnosis for both exposed (children with $\mathrm{AD}$ ) and matched nonexposed children (matched reference children). The reference children had no in- or outpatient hospital diagnosis of AD made by a physician in the study inclusion period.

\section{Exclusion criteria}

Children with comorbidities with a high-risk infectious profile were excluded before index date to focus on children without particularly affected immune responses. Patients with any ICD-10 diagnostic code of HIV (B20-B24), primary immunodeficiency (D70.0, D70.4, D71, 72.0, D76.1, D80-D84, E70.3, G11.3), leukemia and lymphoma (C77, C81-C96), cancers (C30-C39, C40-C41, C43, C45-C49, C51-58, C60, C62-63, C64-C68, C69-C72, C73-C75, C97), diabetes (E10-E14), organ transplant recipients (Z94, T86), chronic renal failure (N18) and cystic fibrosis (E84) were excluded from the source population.

Children with history of prior infections before the index date were not excluded independently of AD status.

\section{Follow-up}

Follow-up for children with AD began at the date of exposure i.e. recorded AD diagnosis (index date). Follow-up for reference children began at the date of matching with child with AD (the index date for the corresponding $\mathrm{AD}$ child). Follow-up ended at the time of outcome or study end 
date (December 31,2017), or their 18th birthday or emigration, or date of death, whichever occurred first. The minimum follow-up was at least one year except in case of censoring (18th birthday or emigration, or death).

\section{Systemic infections leading to hospitalisation}

Systemic infections were infections, regardless of the pathogen, which lead to hospitalisation for more than 24 hours. These were identified by a hospital primary diagnosis through the hospital discharge ICD-10 codes in the DNPR (see Supplementary Table S1). Fungal and parasitic infections were not considered given that these are very rare in Denmark. Systemic infections were grouped as follows: upper respiratory tract, lower respiratory tract, gastrointestinal tract, musculoskeletal tract, urinary tract, heart, central nervous system infections and sepsis.

\section{Covariates}

We used a directed acyclic graph to identify potential confounders of the association between AD and systemic infections leading to hospitalization (see Supplementary Figure S1). The atopic comorbidity status was assessed and defined as follows: definition of asthma based on the ICD-10 code J45-J46 and/or at least two dispensations of a drug for obstructive airway diseases for children over 5 years according to the ATC code R03, recorded in the DNPR and/or the DNPrR), definition of hay fever (definition based on the ICD-10 code J30 and/or at least two dispensations of an antiallergic or corticosteroids nasal spray according to the ATC code R01AC/R01AD, recorded in the DNPR and/or the DNPrR).

The severity of AD was modeled as a time-dependent variable. Four categories (mild, mild-tomoderate, moderate-to-severe and severe) were defined according to dispensations of treatments (topical and systemic immunosuppressants) used in Denmark for AD between index date and censoring for each included individual according to the below list. An individual categorized to a lower category could be re-categorized into any higher category, whereas no re-categorization to a lower category was allowed. The categories were as follows: mild: baseline until entering a higher severity; mild-to-moderate: at the first dispensation of a moderately potent topical corticosteroid (TCS) e.g. hydrocortisone 17-butyrate or first dispensation of topical tacrolimus $0.03 \%$; moderateto-severe: at the first dispensation of a potent TCS e.g. betamethasone or mometasone furoate or first dispensation of topical tacrolimus $0.1 \%$; severe: at the first dispensation of a very potent TCS e.g. clobetasol propionate or first dispensation for systemic immunosuppressants e.g. methotrexate, azathioprine, cyclosporine or mycophenolate mofetil). 
The ATC codes used for topical and systemic immunosuppressants for AD and identified through the DNPrR and the DNPR are given in the Supplementary Table 2.

The use of systemic corticosteroids (ATC codes H02A and H02B) was studied separately because they are not recommended as systemic treatments for $\mathrm{AD}$ and is used exceptionally for $\mathrm{AD}$ for a short term period; it was defined by at least one dispensation identified through the DNPrR and the DNPR during the follow-up, the ATC codes are given in the supplementary Table S2.

The socioeconomic status was assessed by the average family income (father and mother) within the five years before the index date and was divided into quintiles.

\section{Statistical analysis}

Descriptive statistics were expressed as means and standard deviations for normally distributed continuous variables or median and interquartile ranges for non-normally distributed continuous variables, and frequencies for categorical variables. Incidence rates (IRs) per 10,000 person-years and $95 \%$ confidence interval $(\mathrm{CI})$ were calculated by identifying the number of infections and the number of person-years of follow-up for children with AD and reference children separately. To estimate the population impact of pediatric $\mathrm{AD}$ on infection risk, we calculated the absolute risk difference with $95 \%$ CI for each systemic infection as the difference between AD cohort's IRs and reference cohort's IRs. We used Cox regression with calendar time as the underlying timescale to estimate hazard ratios (HRs) with $95 \%$ confidence intervals $(95 \% \mathrm{CI})$ of the association between systemic infections requiring hospitalisation and $\mathrm{AD}$ in childhood (the unadjusted model), with general population without $\mathrm{AD}$ as the reference group. We used the log-log graphic method to assess the proportional hazards assumption. Adjustments for gender, age, socioeconomic status (at the entry in the cohort), atopic comorbidities (asthma and/or hay fever, time-updated variable) and systemic immunosuppressant treatment for AD (time-updated variable) was performed (the adjusted model). We also subgrouped analyses by category of AD severity modeled as a timeupdated variable.

We performed a secondary analysis exploring the definition of infections by including all infections which lead to hospital management (outpatient: visit to emergency unit or outpatient visit hospital or outpatient hospital day stay and inpatient: hospitalisation) and also included subgrouping by AD severity.

\section{Sensitivity analyses}

We performed a sensitivity analysis with adjustment for the use of systemic corticosteroid treatment. Sensitivity analysis also included subgrouping by AD severity. 
Due to the numbers of comparisons and subsequent risk of type I errors, Bonferroni correction was used and p-values $<0.00069$ were considered statistically significant.

\section{Authorizations}

Approval from an ethics committee is not required for register studies in Denmark (Danish law:

Lov om videnskabsetisk behandling af sundhedsvidenskabelige forskningsprojekter, $\S 14$, stk. 2).

This study was approved by the Danish Data Protection Agency (number VD-2018-286).

\section{Results}

We included 19,415 children with AD and 194,150 reference children, with a median follow-up time of $7.4(\mathrm{IQR}=3.3-13.3)$ and $7.7(\mathrm{IQR}=3.6-13.5)$ years, respectively (Figure 1). At entry cohort, half of them were under 2 years and 56\% were boys; asthma and/or allergic rhinitis were more prevalent in children with AD compared with reference children $(13.7 \%$ vs $4.7 \%, \mathrm{p}<0.0001)$ (Table 1). Over the follow-up period, $89 \%$ of children with AD had received at least one dispensation of TCS, $16.2 \%$ a topical calcineurin inhibitor, and $1.6 \%$ a systemic immunosuppressant (Table 1); children with AD treated with a systemic immunosuppressant were older and had more atopic comorbidities compared with children without treatment with systemic immunosuppressant (mean (standard deviation, SD) 6.0 years $(5.0)$ vs 3.6 years $(3.8) ; 63.4 \%$ vs $48.4 \%$, respectively)). Compared with reference children, incidence rates for all categories of systemic infections were increased in children with $\mathrm{AD}$ (Table 2). The absolute risk difference per 10,000 person-years was 26.4 (CI95\% 23.0-29.8) for lower respiratory, 3.1 (CI95\% 1.6-4.7) for upper respiratory, 3.6 (CI95\% 1.8-5.4) for urinary tract, 0.9 (CI95\% 0.2-2.0) for musculoskeletal and 8.7 (CI95\% 5.7-11.7) for gastrointestinal infections. The absolute risk difference for all categories of systemic infection requiring hospitalisation is given in the supplementary material (Table S3). We observed an association between $\mathrm{AD}$ and risk of upper and lower respiratory, gastrointestinal, urinary tract and musculoskeletal infections (Table 2, Figure 2). The strongest associations were for lower and upper respiratory tract infections (respectively, aHR (adjusted $\mathrm{HR})=1.79$, CI95\%1.65-1.94 and $\mathrm{aHR}=1.59$, CI95\%1.34-1.88) and urinary tract infections $(\mathrm{aHR}=1.34$ CI95\%1.16-1.54) (Table 2, Figure 2).

The association with systemic infections did not vary with the severity of AD (Figure 3). In the secondary analysis extending the definition of systemic infections to infections which leads to a hospital management, we found similar findings. The adjusted HRs were 1.39 (CI95\% 1.261.53 ) for upper respiratory tract, 1.77 (CI95\% 1.65-1.90) for lower respiratory tract, 1.44 (CI95\% 1.21-1.72) for musculoskeletal, 1.30 (CI95\% 1.21-1.35) for gastrointestinal tract and 1.21 (CI95\% 
1.09-1.35) for urinary tract infections (Table 3, Figure 4, Figure 5 and supplementary Table S4).

In the sensitivity analysis adjusting for the use of systemic corticosteroids, the results were very close to the main analysis (Supplementary Table S5).

\section{Discussion}

Analysis of Danish nationwide registries over a 20-year period showed that children with AD managed in a hospital in- or outpatient setting had a higher occurrence of infections that required hospitalisation, including upper and lower respiratory tract, gastrointestinal tract, urinary tract and musculoskeletal infections.

Two previous cross-sectional studies investigated the association between childhood AD and extra-cutaneous infections and observed higher prevalence of strep throat, head or chest cold, influenza/pneumonia, sinus infections, recurrent ear infections, chickenpox, and urinary tract infections. ${ }^{9,10}$ The association did not vary with AD severity. ${ }^{9}$ In both studies, ${ }^{9,10} \mathrm{AD}$ and infection diagnoses as well as $\mathrm{AD}$ severity ${ }^{9}$ were based on self-report. We confirm the increased risk of systemic infections, and further show that these demanded hospitalisation, hence indicating severe disease. A cross-sectional study using the hospital discharge data of a $20 \%$ sample of US hospitalisations found higher prevalence of different systemic infections leading to hospitalisation including respiratory infections, encephalitis, endocarditis and arthritis, among adults with AD. ${ }^{12}$ In our study we found no association with central nervous system and heart infections maybe due to an overall low number of cases. This difference may also in part be explained by the inability in the previous study ${ }^{12}$ to adjust for the use of immunosuppressant treatment, which could play a critical role in the pathway between AD and serious infections. ${ }^{22}$ Here, we adjusted for these potential important risk factors, hence allowing us to study the specific contribution from AD. Moreover, unlike the study by Narla et al., ${ }^{12}$ we have investigated the temporality of the association between $\mathrm{AD}$ and systemic infections requiring hospitalization, and to our knowledge, this is the first cohort study focusing strictly on infections requiring hospitalisation among children with AD.

The association with systemic infections did not clearly vary with the severity of AD despite a slight trend towards increased risk from the mild category to the moderate-to-severe category. Surprisingly, we did not observe a higher risk in the-category of severe AD. Some hypotheses could explain this result. First, children treated with immunosuppressant treatment have a thorough assessment focusing among other on infection risk before these medications are prescribed, and they also undergo repeated monitoring. These efforts likely minimize the risk 
children with $\mathrm{AD}$ who are immunosuppressed, and even prevents it use in those who have higher baseline risk of severe infection. Second, systemic treatments for AD could reduce infection risk by improving the skin barrier function and hence the risk of first cutaneous and later systemic infection driven by Staphylococcus aureus. Indeed, a recent meta-analysis of randomized controlled trials of dupilumab for AD concluded that dupilumab treated adult AD patients had a lower incidence of skin infections and eczema herpeticum. ${ }^{22}$ Third, the severity of AD was defined by proxy measures (dispensations of AD treatments) without any information on $\mathrm{AD}$ control and with a potential misclassification bias.

Although the cause of the association between $\mathrm{AD}$ and systemic infections remains unclear, our results might suggest causal mechanisms partly linked to AD itself and not only atopic disease. Indeed, the estimation of the associations with systemic infections remained significant even after adjusting for important atopic comorbidities. For respiratory tract infections, some respiratory symptoms encoded as infections could be actually the first symptoms of undiagnosed asthma, therefore some misclassifications may have occurred. This hypothesis is more plausible in infants (less than 2 years of age) for whom the diagnosis of asthma is defined by at least three or more recurrent wheezing regardless the cause (infectious or not). ${ }^{23}$ Diagnoses of asthma is also more likely to be made in the AD cohort than diagnoses of upper respiratory tract infections; this nondifferential misclassification would bias the effect estimate toward the null, that means that our estimates may be cautious estimates of the association between atopic dermatitis and upper respiratory infections.

Regarding the association between childhood AD and urinary tract infections, two prior studies have found higher prevalence of urinary tract infections among children with AD, a survey-based study including 9,417 children ${ }^{10}$ and a study of 57 infants with a dermatologist-confirmed AD diagnosis and 57 controls including systematic urine samples. ${ }^{24}$ Some hypotheses might be considered: systemic immune dysfunction linked to $\mathrm{AD},{ }^{25}$ scratching in genital area which could be a portal of entry for bacteria or a random finding.

The exhaustiveness of infections requiring hospitalisation at nationwide level, a follow-up period over 20 years and physician-confirmed diagnoses both for AD and infectious diseases are among the strengths of our study, as is the quality of the information enabling in theory no loss of followup and no attrition bias.

Some potential limitations should be discussed. First, the population was all children with a hospital diagnosis with $\mathrm{AD}$ and the results could not be generalized to the $\mathrm{AD}$ population of 
children seen in primary care. We nevertheless had access to all dermatologist records, from hospitals and some private clinics giving it relevance to AD patients seen by dermatologists in general. Moreover, AD diagnosed outside hospital may have occurred in the reference group but this would tend to underestimate difference. Second, we did not have clinical details outside the hospital discharge codes notably on the disease flares and the effect of AD treatment on AD control, the question is here "when" rather than "who" and our design could not address this question. Third, we have studied the association with systemic infections regardless of the pathogen. Fourth, we did not study the early antibiotic exposure before the diagnosis of AD and the vaccination status which could play a role in the development of $\mathrm{AD}$ and severe infectious diseases. ${ }^{26,27}$ Obesity could also be a potential confounding or intermediate factor in the study of the association between childhood AD and infections, but we did not have the possibility to take into account the body mass index because unavailable in the registries. Fifth, our findings that children with $\mathrm{AD}$ have an increased risk of developing systemic infections requiring hospital care could be due to surveillance bias. Nevertheless, this bias is less likely for infections requiring hospitalisation and the adjustment on the number of hospital visits neither confirm nor invalidate the evidence of surveillance bias (data not shown). At last, the absolute risk difference between children with $\mathrm{AD}$ and reference children was small; for example, if we followed 5,000 children with $\mathrm{AD}$ for 2 years, we might expect 3 excess upper respiratory infections due to their $\mathrm{AD}$.

\section{Conclusion}

We found that children with AD have an increased risk of developing systemic infections that lead to hospitalisation for respiratory tract, gastrointestinal, urinary tract and musculoskeletal infections. Associations were not explained by other atopic comorbidity or use of immunosuppressive treatment. While the risk for these infectious diseases was elevated among children with $\mathrm{AD}$, the absolute risk was low. 


\section{Acknowledgments}

The authors are grateful to the Fondation de la Dermatite Atopique, the Collège des Enseignements en Dermatologie (CEDEF) and the International Society of Atopic Dermatitis for their support. 


\section{References}

1. Langan SM, Irvine AD, Weidinger S. Atopic dermatitis. Lancet. 2020, 396:345-360.

2. Odhiambo JA, Williams HC, Clayton TO, et al. ISAAC Phase Three Study Group. Global variations in prevalence of eczema symptoms in children from ISAAC Phase Three. J Allergy Clin Immunol. 2009, 124:1251-8.e23.

3. Ong PY, Leung DY. Bacterial and viral infections in atopic dermatitis: a comprehensive review. Clin Rev Allergy Immunol. 2016, 51:329e37.

4. Meylan P, Lang C, Mermoud S, et al. Skin Colonization by Staphylococcus aureus Precedes the Clinical Diagnosis of Atopic Dermatitis in Infancy. J Invest Dermatol. 2017, 137:2497-2504.

5. Beck LA, Boguniewicz M, Hata T, et al. Phenotype of atopic dermatitis subjects with a history of eczema herpeticum. J Allergy Clin Immunol. 2009, 124:260-9.

6. Hsu DY, Shinkai K, Silverberg JI. Epidemiology of Eczema Herpeticum in Hospitalized U.S. Children: Analysis of a Nationwide Cohort. J Invest Dermatol. 2018, 138:265-272.

7. Serrano L, Patel KR, Silverberg JI. Association between atopic dermatitis and extracutaneous bacterial and mycobacterial infections: A systematic review and meta-analysis. J Am Acad Dermatol. 2019, 80:904-912.

8. Paternoster L, Standl M, Waage J, et al. Multi-ancestry genome-wide association study of 21,000 cases and 95,000 controls identifies new risk loci for atopic dermatitis. Nat Genet. 2015, 47:1449-1456.

9. Silverberg JI, Simpson EL. Association between severe eczema in children and multiple comorbid conditions and increased health care utilization. Pediatr Allergy Immunol. 2013, 24:47686.

10. Silverberg J, Silverberg N. Childhood atopic dermatitis and warts are associated with increased risk of infection: a US population-based study. J Allergy Clin Immunol. 2014, 133:1041-7.

11. Langan SM, Abuabara K, Henrickson SE, et al. Increased Risk of Cutaneous and Systemic Infections in Atopic Dermatitis-A Cohort Study. J Invest Dermatol. 2017, 137:13751377.

12. Narla S, Silverberg JI. Association between childhood atopic dermatitis, cutaneous, extracutaneous and systemic infections. Br J Dermatol. 2018, 178:1467-1468.

13. Schmidt M, Pedersen L, Sørensen HT. The Danish Civil Registration System as a tool in epidemiology. Eur J Epidemiol. 2014, 29:541-9. 
14. Pedersen CB. The Danish Civil Registration System. Scand J Public Health 2011, 39:22-5.

15. Andersen TF, Madsen M, Jorgensen J, et al. The Danish national hospital register. A valuable source of data for mod- ern health sciences. Dan Med Bull. 1999, 46:263-268.

16. Andersen JS, Olivarius Nde F, Krasnik A. The Danish National Health Service Register. Scand J Public Health. 2011, 39:34-7.

17. Lynge E, Sandegaard JL, Rebolj M. The Danish National Patient Register. Scand J Public Health. 2011, 39:30-3.

18. Schmidt M, Schmidt SAJ, Sandegaard JL, et al. The Danish National Patient Registry: a review of content, data quality, and research potential. Clin Epidemiol. 2015, 7:449-90.

19. Kildemoes HW, Sørensen HT, Hallas J. The Danish National Prescription Registry. Scand J Public Health. 2011 Jul, 39:38-41.

20. Baadsgaard M, Quitzau J. Danish Registers on Personal Income and Transfer Payments. Scand J Public Health. 2011, 39:103-5.

21. Andersen YMF, Egeberg A, Skov A, Thyssen JP. Demographics, Healthcare Utilization and Drug Use in Children and Adults With Atopic Dermatitis in Denmark: A Population-Based CrossSectional Study. J Eur Acad Dermatol Venereol. 2019, 33: 1133-1142.

22. Fleming P, Drucker AM. Risk of infection in patients with atopic dermatitis treated with dupilumab: A meta-analysis of randomized controlled trials. J Am Acad Dermatol. 2018, 78:6269.

23. Tabachnik E, Levison H. Postgraduate course presentation. Infantile bronchial asthma. J Allergy Clin Immunol. 1981, 67:339-47.

24. Farajzadeh S, Ghazanfari F, Esfandiarpour I, Shahesmaeili A, Rahnama Z, Aghaei H. The Relationship Between Infantile Atopic Dermatitis and Urinary Tract Infection. Iran J Allergy Asthma Immunol. 2009, 8:211-4.

25. Yang G, Seok JK, Kang HC, Cho YY, Lee HS, Lee JY. Skin Barrier Abnormalities and Immune Dysfunction in Atopic Dermatitis. J Mol Sci. 2020, 21: 2867.

26. Tsakok T, McKeever TM, Yeo L, Flohr C. Does early life exposure to antibiotics increase the risk of eczema? A systematic review. Br J Dermatol 2013, 169:983e91.

27. Tamburini S, Shen N, Chih WU H, Clemente J. The microbiome in early life: implications for health outcomes. Nat Med . 2016, 22:713-22. 
Table 1: Descriptive characteristics of the non-exposed cohort (reference children) and the exposed cohort (children with atopic dermatitis) at the index date and during the follow-up

\begin{tabular}{|c|c|c|}
\hline & $\begin{array}{c}\text { Reference children } \\
\mathrm{N}=\mathbf{1 9 4 , 1 5 0}\end{array}$ & $\begin{array}{c}\text { AD }^{\mathrm{a}} \text { children } \\
\mathrm{N}=\mathbf{1 9 , 4 1 5}\end{array}$ \\
\hline \multicolumn{3}{|l|}{ At index date } \\
\hline \multicolumn{3}{|l|}{ Gender, n (\%) } \\
\hline Boys & $108,880(56.08)$ & $10,888(56.08)$ \\
\hline Girls & $85,270(43.92)$ & $8,527(43.92)$ \\
\hline \multicolumn{3}{|l|}{ Age, years } \\
\hline Median (IQR) & $2.09(0.98-4.82)$ & $2.09(0.98-4.82)$ \\
\hline Mean (+/-SD) & $3.66(3.92)$ & $3.66(3.92)$ \\
\hline$<1, \mathrm{n}(\%)$ & $49,350(25.42)$ & $4,935(25.42)$ \\
\hline$>=1-<2, \mathrm{n}(\%)$ & $44,510(22.93)$ & $4,451(22.93)$ \\
\hline$>=2-<5, \mathrm{n}(\%)$ & $53,410(27.51)$ & $5,341(27.51)$ \\
\hline$>=5-<10, \mathrm{n}(\%)$ & $28,360(14.61)$ & $2,836(14.61)$ \\
\hline$>=10-<15, \mathrm{n}(\%)$ & $13,760(9.09)$ & $1,376(9.09)$ \\
\hline$>=15, \mathrm{n}(\%)$ & $4,760(2.45)$ & $476(2.45)$ \\
\hline History of asthma and/or hay feverb ${ }^{\mathrm{b}} \mathrm{n}(\%)$ & $9,178(4.73)$ & $2,653(13.66)$ \\
\hline \multicolumn{3}{|l|}{$\begin{array}{l}\text { Socioeconomic status } \mathbf{c}, \mathbf{n}(\%) \\
\text { (five categories) }\end{array}$} \\
\hline Lowest & $38,482(19.85)$ & $4,166(21.46)$ \\
\hline Below average & $38,585(19.91)$ & $4,062(20.93)$ \\
\hline Average & $38,898(20.07)$ & $3,750(19.32)$ \\
\hline Above average & $38,980(20.11)$ & $3,668(18.90)$ \\
\hline Highest & $38,884(19.9)$ & $3,763(19.39)$ \\
\hline Missing & $321(0.16)$ & $6(0.00)$ \\
\hline \multicolumn{3}{|l|}{ Over the follow-up period } \\
\hline Asthma and/or hay fever ${ }^{b}$ & $30,935(15.93)$ & $9,440(48.62)$ \\
\hline $\begin{array}{l}\text { Systemic corticosteroids (at least one } \\
\text { dispensation), } \mathbf{n}(\%)\end{array}$ & $2,339(1.20)$ & $897(4.62)$ \\
\hline $\begin{array}{l}\text { Long-term systemic corticosteroids (more } \\
\text { than six weeks), n (\%) }\end{array}$ & $258(0.13)$ & $77(0.40)$ \\
\hline $\begin{array}{l}\text { Oral immunosuppressant treatment for } \\
\text { AD, n (\%) }\end{array}$ & & \\
\hline
\end{tabular}




\begin{tabular}{|l|l|l|}
\hline Cyclosporine & $11(0.01)$ & $52(0.27)$ \\
\hline Methotrexate & $138(0.07)$ & $179(0.92)$ \\
\hline Azathioprine & $113(0.06)$ & $146(0.75)$ \\
\hline Mycophenolate mofetil & $3(0.00)$ & $11(0.06)$ \\
\hline
\end{tabular}

Abbreviations: N, number of adult patients; IQR, interquartile range; SD, standard deviation.

${ }^{a}$ Atopic dermatitis made by a hospital physician during childhood, using the diagnostic J20 code of the International Classification of Diseases 10 th revision

b Asthma (based on the ICD-10 code J45-J46 and/or at least two dispensations of a drug for obstructive airway diseases for children over 5 years according to the ATC code R03, recorded in the DNPR and/or the RMPS), hay fever (based on the ICD-10 code J30 and/or at least two dispensations of a antiallergic or corticosteroids nasal spray according to the ATC code R01AC/R01AD, recorded in the DNPR and/or the RMPS) ${ }^{\mathrm{c}}$ based on family income at index date; study population divided into quintiles 
Table 2: Association between atopic dermatitis and serious infections (only infections requiring hospitalisation) (Main Analysis)

\begin{tabular}{|c|c|c|c|c|c|c|c|}
\hline \multirow{2}{*}{ Outcomes ${ }^{\mathrm{c}}$} & \multirow{2}{*}{$\begin{array}{l}\text { Patient year } \\
\text { at risks }\end{array}$} & \multirow{2}{*}{$\begin{array}{c}\text { Number of } \\
\text { events }\end{array}$} & \multirow{2}{*}{$\begin{array}{c}\text { Absolute incidence } \\
\operatorname{rate}^{\mathrm{a}}(\mathrm{CI} 95 \%)\end{array}$} & \multicolumn{2}{|c|}{ Crude Model } & \multicolumn{2}{|c|}{ Adjusted $^{\mathrm{b}}$ Model } \\
\hline & & & & HR (CI95\%) & P value & HR (CI95\%) & P value \\
\hline \multicolumn{8}{|c|}{$\begin{array}{l}\text { Upper respiratory } \\
\text { tract infections }\end{array}$} \\
\hline $\begin{array}{l}\text { Reference } \\
\text { children }\end{array}$ & $1,726,539$ & 1,124 & $6.51(6.14-6.90)$ & 1 (Ref) & & 1 (Ref) & \\
\hline AD children & 173,764 & 168 & $9.66(8.31-11.25)$ & $1.49(1.26-1.75)$ & $<0.0001$ & $1.59(1.34-1.88)^{*}$ & $<0.0001$ \\
\hline \multicolumn{8}{|c|}{$\begin{array}{l}\text { Lower respiratory } \\
\text { tract infections }\end{array}$} \\
\hline $\begin{array}{l}\text { Reference } \\
\text { children }\end{array}$ & $1,700,473$ & 3,873 & $22.77(22.06-23.50)$ & 1 (Ref) & & 1 (Ref) & \\
\hline AD children & 167,484 & 824 & $49.20(45.95-52.67)$ & $2.15(1.99-2.31)$ & $<0.0001$ & $1.79(1.65-1.94)^{*}$ & $<0.0001$ \\
\hline \multicolumn{8}{|l|}{$\begin{array}{l}\text { Gastrointestinal } \\
\text { tract infections }\end{array}$} \\
\hline $\begin{array}{c}\text { Reference } \\
\text { children }\end{array}$ & $1,706,332$ & 4,891 & $28.66(27.87-29.48)$ & 1 (Ref) & & 1 (Ref) & \\
\hline AD children & 171,245 & 640 & $37.37(34.59-40.38)$ & $1.30(1.20-1.41)$ & $<0.0001$ & $1.24(1.14-1.35)^{*}$ & $<0.0001$ \\
\hline \multicolumn{8}{|l|}{$\begin{array}{c}\text { Urinary tract } \\
\text { infections }\end{array}$} \\
\hline $\begin{array}{l}\text { Reference } \\
\text { children }\end{array}$ & $1,732,336$ & 1,732 & $10.05(9.59-10.53)$ & 1 (Ref) & & 1 (Ref) & \\
\hline AD children & 173,381 & 236 & $13.61(11.98-15.46)$ & $1.36(1.18-1.55)$ & $<0.0001$ & $1.34(1.16-1.54)^{*}$ & $<0.0001$ \\
\hline \multicolumn{8}{|c|}{$\begin{array}{l}\text { Musculoskeletal } \\
\text { tract infections }\end{array}$} \\
\hline $\begin{array}{l}\text { Reference } \\
\text { children }\end{array}$ & $1,727,515$ & 741 & $4.29(3.99-4.61)$ & 1 (Ref) & & 1 (Ref) & \\
\hline AD children & 174,085 & 91 & $5.23(4.26-6.42)$ & $1.22(0.98-1.52)$ & 0.0729 & $1.33(1.06-1.66)$ & 0.014 \\
\hline \multicolumn{8}{|c|}{$\begin{array}{l}\text { Central nervous } \\
\text { system infections }\end{array}$} \\
\hline $\begin{array}{l}\text { Reference } \\
\text { children }\end{array}$ & $1,732,046$ & 215 & $1.24(1.09-1.42)$ & 1 (Ref) & & 1 (Ref) & \\
\hline AD children & 174,656 & 32 & $1.83(1.29-2.59)$ & $1.47(1.02-2.14)$ & 0.0396 & $1.43(0.97-2.12)$ & 0.071 \\
\hline \multicolumn{8}{|l|}{ Heart infections } \\
\hline $\begin{array}{l}\text { Reference } \\
\text { children }\end{array}$ & $1,733,067$ & 31 & $0.18(0.16-0.25)$ & 1 (Ref) & & 1 (Ref) & \\
\hline $\mathrm{AD}$ children & 174,785 & 6 & $0.34(0.15-0.76)$ & $1.92(0.80-4.59)$ & 0.1450 & $1.33(0.53-3.36)$ & 0.537 \\
\hline Sepsis & & & & & & & \\
\hline $\begin{array}{c}\text { Reference } \\
\text { children }\end{array}$ & $1,731,924$ & 203 & $1.17(1.02-1.35)$ & $1(\operatorname{Ref})$ & & 1 (Ref) & \\
\hline AD children & 174,646 & 28 & $1.60(1.11-2.32)$ & $1.37(0.92-2.03)$ & 0.1173 & $1.30(0.86-1.97)$ & 0.217 \\
\hline
\end{tabular}

Abbreviations: $\mathrm{AD}$, atopic dermatitis; HR, hazard ratio; CI, confidence interval; Ref, reference 
${ }^{\text {a }}$ per 10,000 person years

${ }^{\mathrm{b}}$ Adjusted on age, gender, socioeconomic level (at the index date), systemic immunosuppressant treatment for AD (time-updated variable) and atopic comorbidities (asthma and/or hay fever, time-updated variable)

${ }^{\mathrm{c}}$ Categories of infection defined using the diagnostic codes of the International Classification of Diseases 10th revision listed in Table S1, in the Supplementary Material.

Significance after Bonferroni correction is marked by * 
Table 3: Association between atopic dermatitis and serious infections (infections with hospital health contact) (Secondary Analysis)

\begin{tabular}{|c|c|c|c|c|c|c|c|}
\hline \multirow{2}{*}{ Outcomes $^{\mathrm{c}}$} & \multirow{2}{*}{$\begin{array}{c}\text { Patient year } \\
\text { at risks }\end{array}$} & \multirow{2}{*}{$\begin{array}{c}\text { Number of } \\
\text { events }\end{array}$} & \multirow{2}{*}{$\begin{array}{c}\text { Absolute incidence } \\
\text { rate }^{\text {a }} \text { (CI95\%) }\end{array}$} & \multicolumn{2}{|c|}{ Crude Model } & \multicolumn{2}{|c|}{ Adusted $^{\mathrm{b}}$ Model } \\
\hline & & & & HR (95\%) & P value & HR (95\%) & P value \\
\hline $\begin{array}{c}\text { Upper } \\
\text { respiratory trac } \\
\text { infections }\end{array}$ & & & & & & & \\
\hline $\begin{array}{l}\text { Reference } \\
\text { children }\end{array}$ & $1,717,618$ & 3,843 & $22.37(21.68-23.09)$ & 1 (Ref) & & 1 (Ref) & \\
\hline AD children & 172,624 & 490 & $28.38(25.98-31.01)$ & $1.27(1.16-1.40)$ & $<0.0001$ & $1.39(1.26-1.53)^{*}$ & $<0.0001$ \\
\hline $\begin{array}{c}\text { Lower } \\
\text { respiratory trac } \\
\text { infections }\end{array}$ & & & & & & & \\
\hline $\begin{array}{l}\text { Reference } \\
\text { children }\end{array}$ & $1,694,861$ & 5,111 & $30.15(29.34-30.99)$ & 1 (Ref) & & 1 (Ref) & \\
\hline AD children & 166,310 & 1,038 & $62.41(58.73-66.33)$ & $2.05(1.92-2.20)$ & $<0.0001$ & $1.77(1.65-1.90)^{*}$ & $<0.0001$ \\
\hline $\begin{array}{l}\text { Gastrointestina } \\
\text { tract infections }\end{array}$ & & & & & & & \\
\hline $\begin{array}{c}\text { Reference } \\
\text { children }\end{array}$ & $1,700,699$ & 6,534 & $38.42(37.50-39.36)$ & 1 (Ref) & & 1 (Ref) & \\
\hline $\mathrm{AD}$ children & 170,403 & 861 & $50.53(47.26-54.02)$ & $1.32(1.23-1.41)$ & $<0.0001$ & $1.30(1.21-1.35)^{*}$ & $<0.0001$ \\
\hline $\begin{array}{l}\text { Urinary tract } \\
\text { infections }\end{array}$ & & & & & & & \\
\hline $\begin{array}{l}\text { Reference } \\
\text { children }\end{array}$ & $1,715,871$ & 3,282 & $19.13(18.48-19.79)$ & 1 (Ref) & & 1 (Ref) & \\
\hline AD children & 172,440 & 407 & $23.60(21.42-26.01)$ & $1.23(1.11-1.37)$ & $<0.0001$ & $1.21(1.09-1.35)^{*}$ & $<0.0001$ \\
\hline $\begin{array}{r}\text { Musculoskeleta } \\
\text { tract infections }\end{array}$ & & & & & & & \\
\hline $\begin{array}{c}\text { Reference } \\
\text { children }\end{array}$ & $1,731,829$ & 1131 & $6.55(6.18-6.95)$ & 1 (Ref) & & 1 (Ref) & \\
\hline AD children & 174,560 & 156 & $8.98(7.68-10.51)$ & $1.37(1.16-1.62)$ & 0.0002 & $1.44(1.21-1.72)^{*}$ & $<0.0001$ \\
\hline $\begin{array}{l}\text { Central nervou } \\
\text { system infection }\end{array}$ & & & & & & & \\
\hline $\begin{array}{c}\text { Reference } \\
\text { children }\end{array}$ & $1,731,829$ & 258 & $1.49(1.32-1.68)$ & 1 (Ref) & & 1 (Ref) & \\
\hline $\mathrm{AD}$ children & 174,650 & 34 & $1.95(1.39-2.72)$ & $1.31(0.91-1.87)$ & 0.1410 & $1.26(0.86-1.83)$ & 0.5570 \\
\hline Heart infection & & & & & & & \\
\hline $\begin{array}{c}\text { Reference } \\
\text { children }\end{array}$ & $1,733,050$ & 39 & $0.22(0.16-0.31)$ & 1 (Ref) & & 1 (Ref) & \\
\hline $\mathrm{AD}$ children & 174,779 & 7 & $0.40(0.19-0.84)$ & $1.78(0.79-3.97)$ & 0.1614 & $1.23(0.53-2.86)$ & 0.633 \\
\hline Sepsis & & & & & & & \\
\hline $\begin{array}{l}\text { Reference } \\
\text { children }\end{array}$ & $1,731,793$ & 221 & $1.27(1.12-1.45)$ & 1 (Ref) & & 1 (Ref) & \\
\hline
\end{tabular}




\begin{tabular}{|c|c|c|c|c|c|c|c|}
\hline AD children & 174,604 & 33 & $1.89(1.34-2.66)$ & $1.48(1.03-2.14)$ & 0.0346 & $1.46(1.00-2.15)$ & 0.053 \\
\hline
\end{tabular}

Abbreviations: $\mathrm{AD}$, atopic dermatitis, $\mathrm{HR}$, hazard ratio; $\mathrm{CI}$, confidence interval; Ref, reference

${ }^{a}$ per 10,000 person years

${ }^{\mathrm{b}}$ Adjusted on age, gender, socioeconomic level (at the index date), systemic immunosuppressant treatment (time-updated variable) and atopic comorbidities (asthma and/or hay fever, time-updated variable)

${ }^{c}$ Categories of infection defined using the diagnostic codes of the International Classification of Diseases $10^{\text {th }}$ revision listed in Table $\mathrm{S} 1$ in the Supplementary Material.

Significance after Bonferroni correction is marked by * 
Figure 1: Flow chart

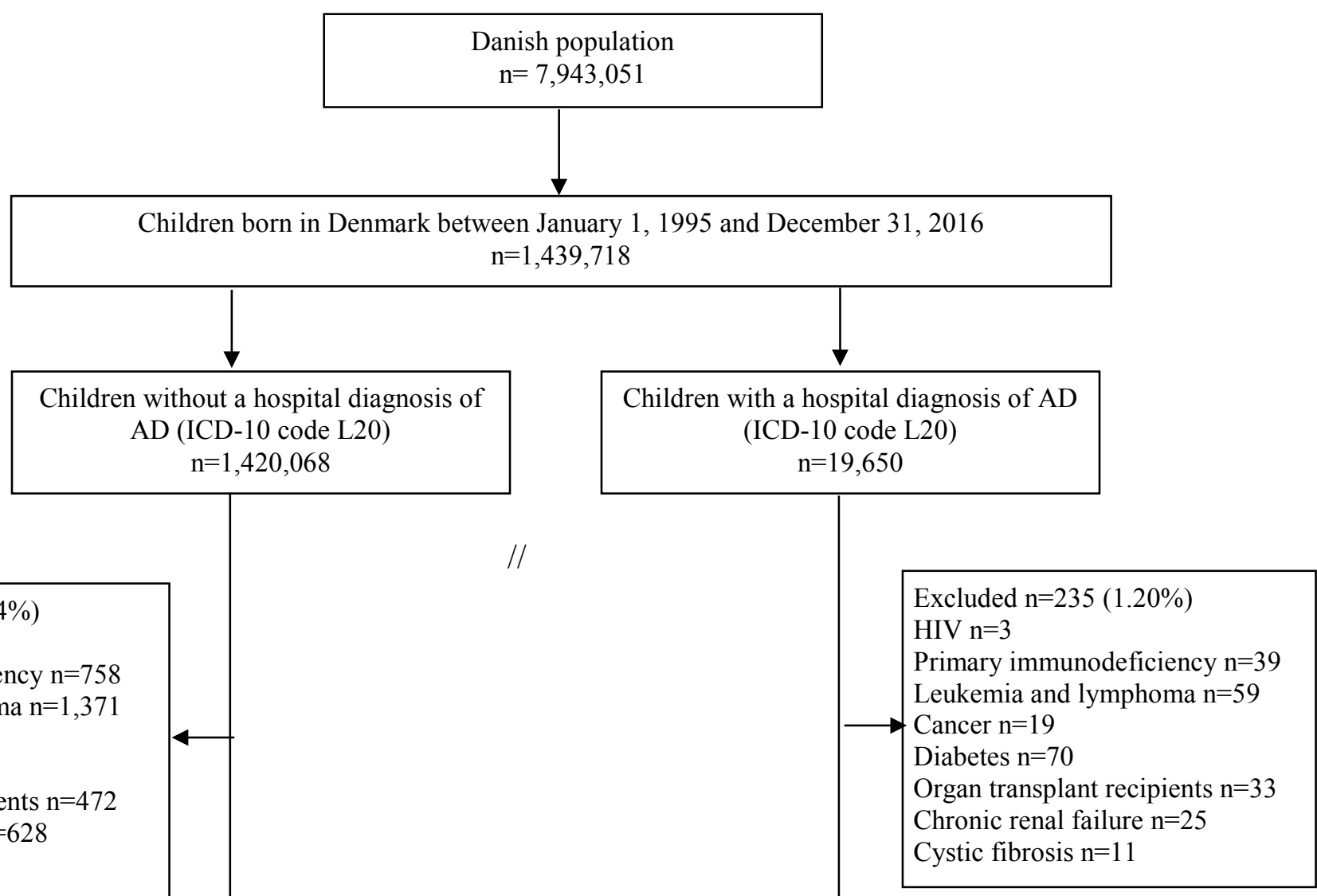

Excluded $\mathrm{n}=9,134(0.64 \%)$

HIV $n=101$

Primary immunodeficiency $\mathrm{n}=758$

Leukemia and lymphoma $\mathrm{n}=1,371$

Cancer $\mathrm{n}=1,385$

Diabetes $\mathrm{n}=4,799$

Organ transplant recipients $n=472$

Chronic renal failure $\mathrm{n}=628$

Cystic fibrosis $n=350$

Matched on age and gender at index date 1:10 
Figure 2: Association between atopic dermatitis and serious infections (only infections requiring hospitalisation) (Main Analysis)

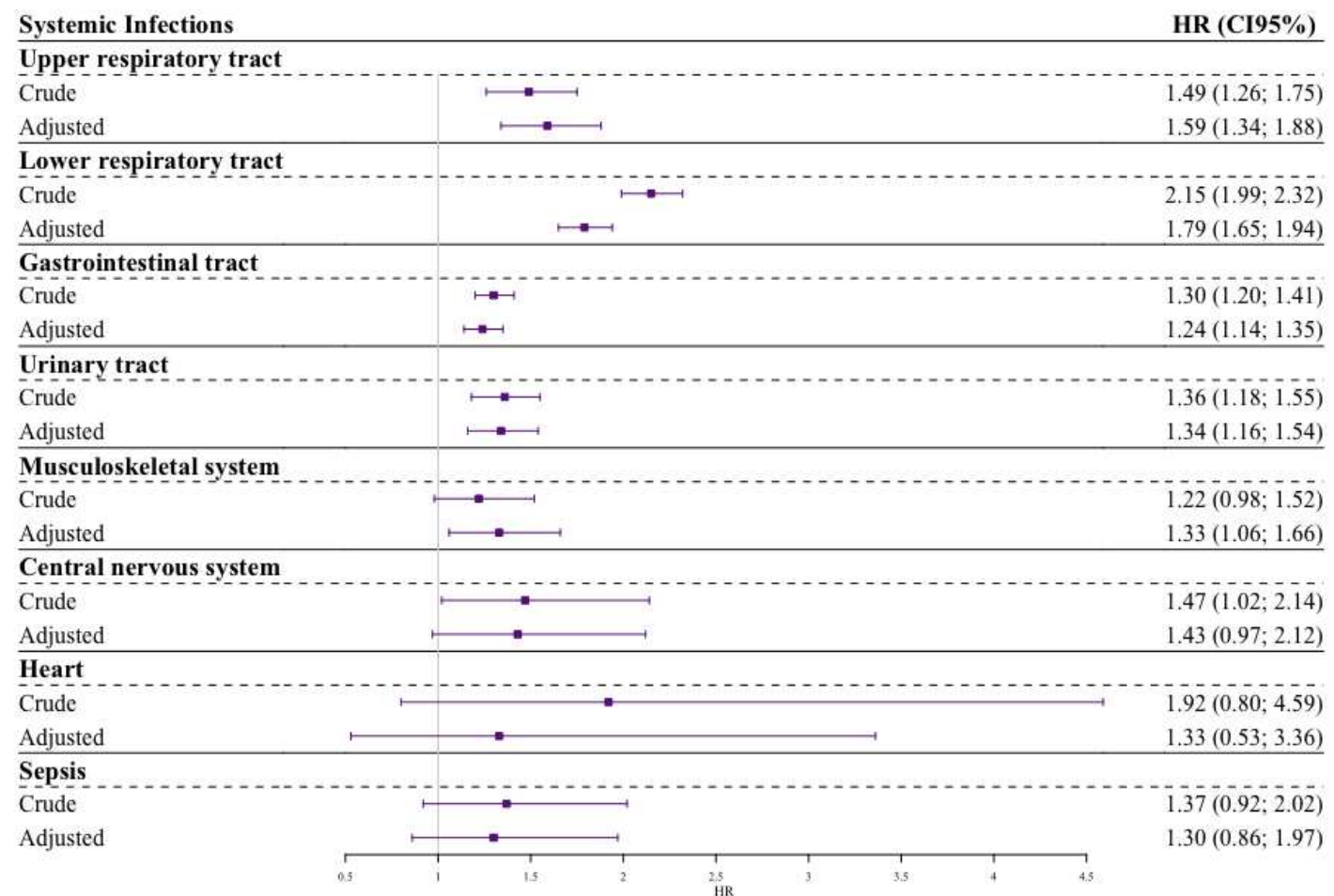

Adjusted on age, gender, socioeconomic level (at the index date), systemic immunosuppressant treatment for AD (time-updated variable) and atopic comorbidities (asthma and/or hay fever, time-updated variable) 
Figure 3: Association between atopic dermatitis and serious infections (only infections requiring hospitalisation) according to AD severity (Main analysis, adjusted model)

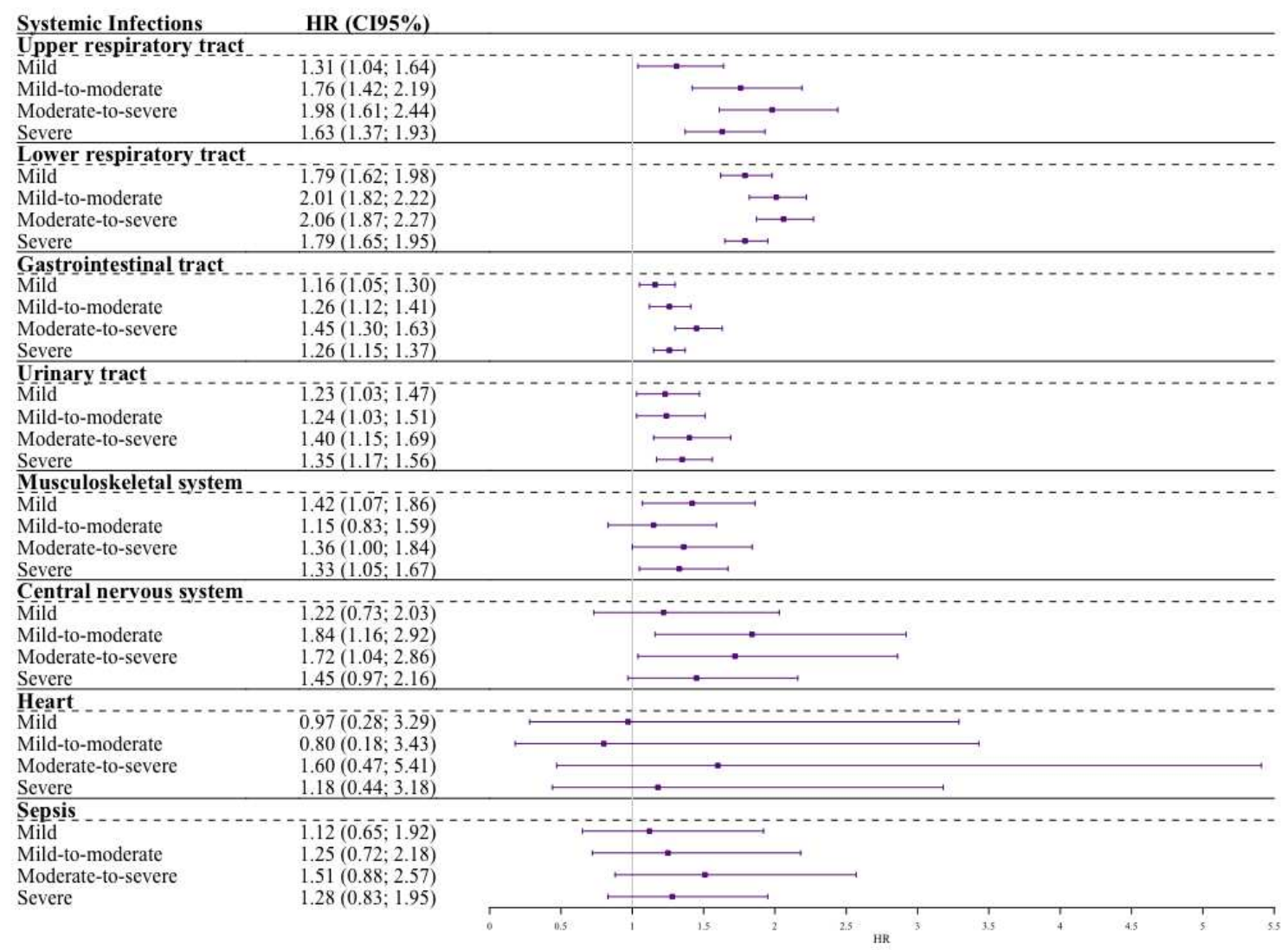


Figure 4: Association between atopic dermatitis and serious infections (infections with hospital health contact) (Secondary Analysis)

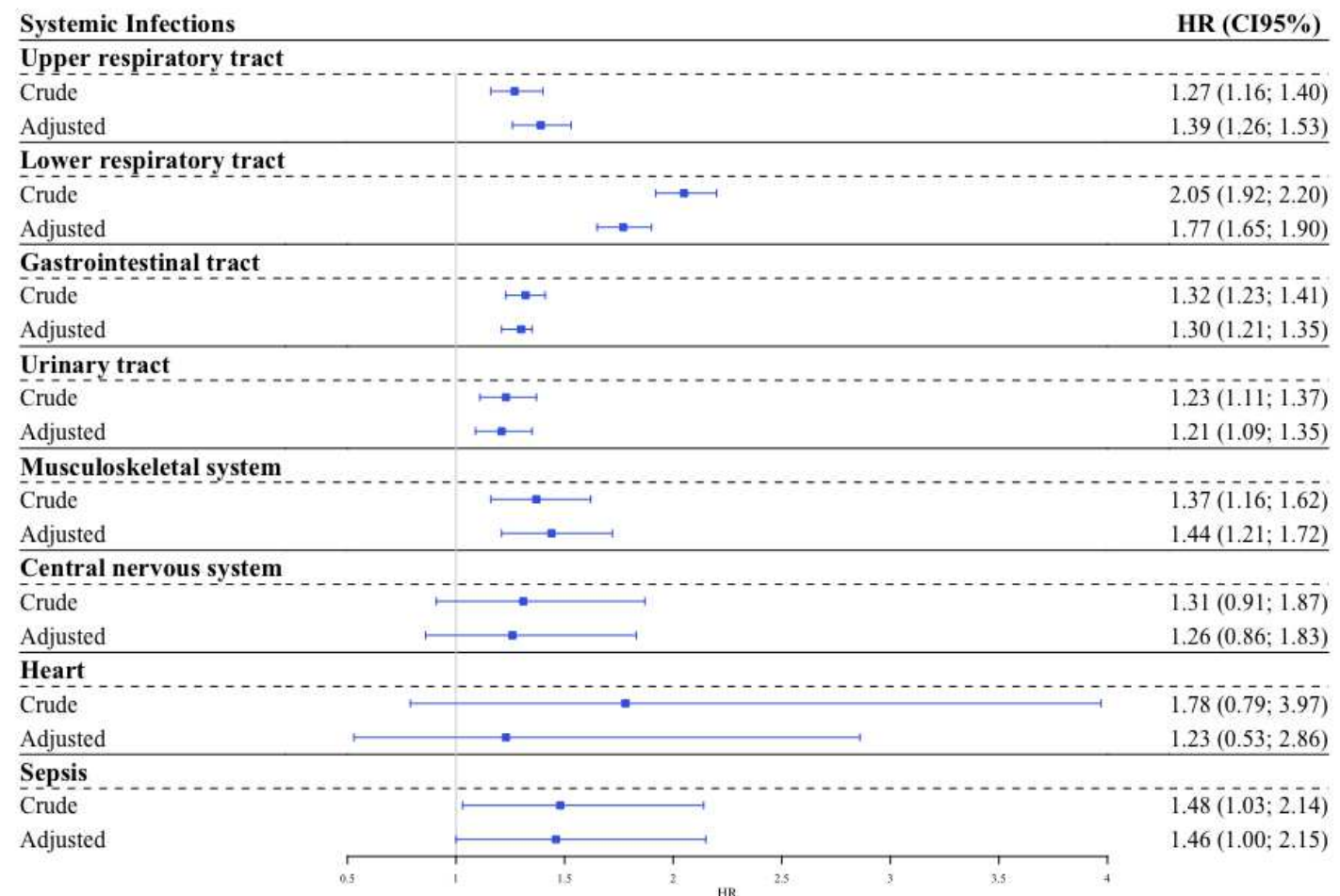

Adjusted on age, gender, socioeconomic level (at the index date), systemic immunosuppressant treatment for AD (time-updated variable) and atopic comorbidities (asthma and/or hay fever, time-updated variable) 
Figure 5: Association between atopic dermatitis and serious infections (infections with hospital health contact) according to AD severity (Secondary analysis, adjusted model)

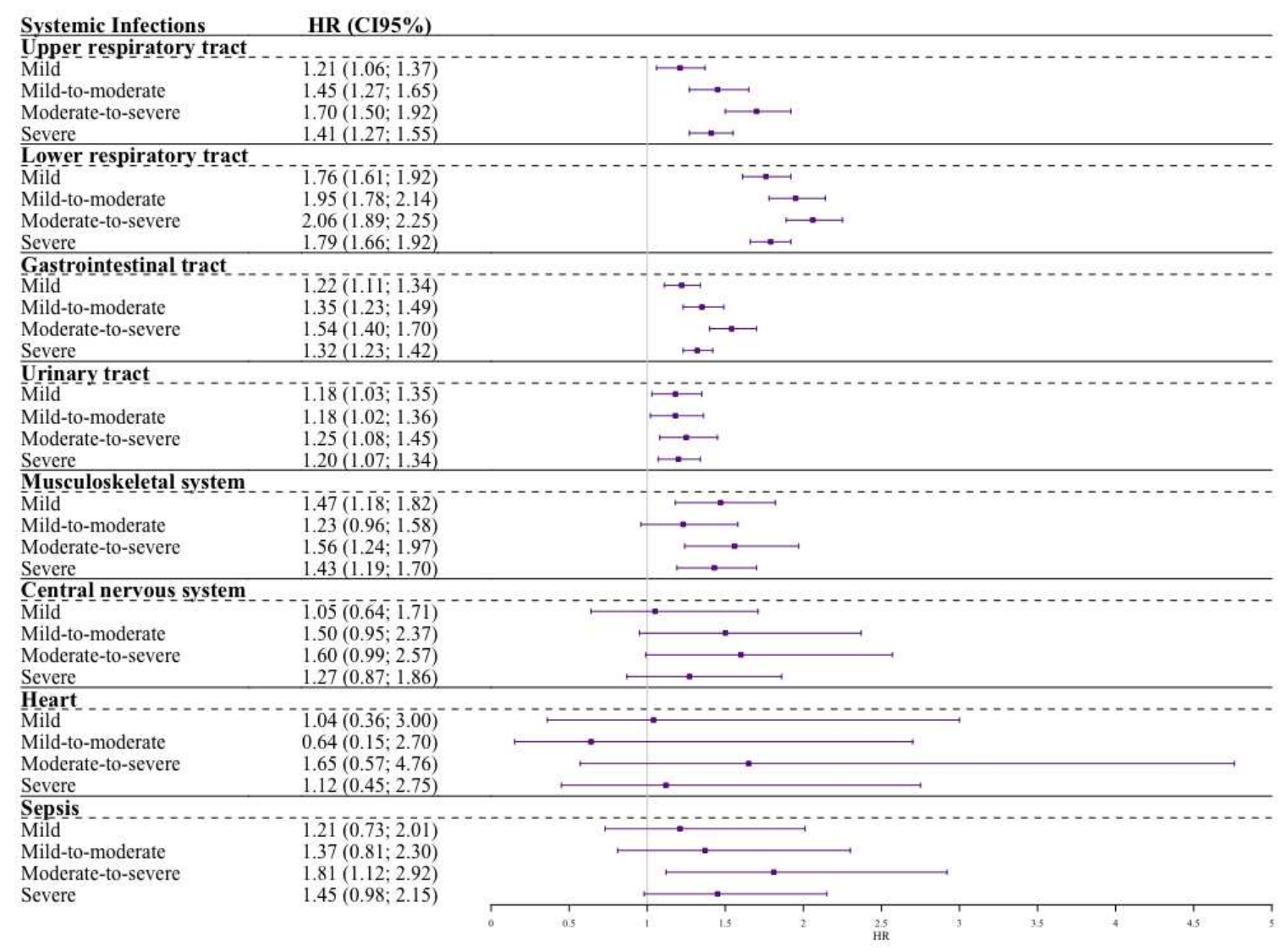

Adjusted on age, gender, socioeconomic level (at the index date) and atopic comorbidities (asthma and/or hay fever) as a time-updated variable) 